\title{
RHEUMATOID ARTHRITIS IN NON-CAUCASIAN POPULATION: EPIDEMIOLOGICAL DATA
}

\author{
Cristina Suta, Maria Suta, Elvira Craiu \\ The $2^{\text {nd }}$ Clinical Department, Faculty of Medicine, Ovidius University, Constanta
}

\begin{abstract}
Rheumatoid arthritis (RA) is a common autoimmune systemic inflammatory disease with still unknown cause. A robust hypothesis for the occurence of the disease is the result of an environmental exposure in a genetically susceptible individual. The risk of RA varies by ethnicity: the majority of the Caucasian populations reported a prevalence of 0.5 to $1 \%$ for this disease; higher prevalences were observed in American Indian tribes and lower ones, in countries of Africa and Asia. This regional variation in the prevalence of RA sustains the involvement of both genetic and enviromental factors in the occurence of this condition.
\end{abstract}

Keywords: rheumatoid arthritis, epidemiology, non-Caucasian population

Rheumatoid arthritis (RA) remains a disease with unsolved etiology, the environmental and genetic factors contributing almost equally to the occurrence of this condition. The risk of RA occurrence varies by ethnicity: the majority of the Caucasian populations reported a prevalence between 0.5 and $1 \%$ for rheumatoid arthritis (RA) (1); higher prevalences were observed in American Indian tribes $(2,3)$ and lower prevalences, in countries of Africa and Asia $(4,5,6)$.

\section{DATA ABOUT RA EPIDEMIOLOGY IN AMERINDIAN POPULATIONS}

The highest prevalence of the disease registers in Native Americans population (Pima Indian tribes, Chippewa, and Yakima) (2,3). Evaluation by X-rays of the adult population of these tribes estimated a prevalence of RA of 3.2-4.8\% for men and 5.9-7\% for women, while among the general population of the United States (US ) there is a prevalence of $0.7 \%$ for men and $1.6 \%$ for women; RA epidemiology data in the US are the results of a clinical trial during 1960-1962, which included individuals aged 18-79 years, who have performed X-rays of the hands and feet and determinations of rheumatoid factor (7).
The Amerindian lineage also increases the risk of RA occurrence: thus, in Yucatan peninsula where Amerindian origin is common, the prevalence of RA is five times higher than in other regions of Mexico (8).

\section{RA EPIDEMIOLOGY IN AFRICA (NEGROID RACE)}

A great number of clinical and epidemiological data about RA come early in time from the African continent. According to preliminary reports regarding Central Africa (Gelfand, 1957), Malawi (Goodall, 1956), Uganda (Shaper and Shaper, 1958) and then Nigeria (Greenwood, 1969), RA is a rare and relatively mild disease representing a rare cause of hospitalization in tropical Africa. The analysis of 71 cases of RA (according to ARA diagnostic criteria) admitted to University College Hospital in Ibadan, Nigeria or from hospital outpatient department, during 1957-1967, showed a low incidence of extra-articular manifestations (nodules, vasculitis, peripheral neuropathy), a low rate of positive rheumatoid factor (RF) (13\%, similar to the control group), mild radiographic changes and a good prognosis. A distinct form of the disease has been suggested, a somehow modified form of RA under the influence 
of tropical climate factors (9). In 1970, the prevalence of „defined” and ,probable” RA in western Nigeria and in Liberia is estimated at $0.8 \%, 1.6 \%$ and $2.8 \%$ in three different villages (10).

Results of two prospective epidemiological studies on the prevalence of RA in the black population of urban and rural areas of South Africa are published in 1975. The diagnosis of "defined" and "probable" RA was established as per Rome criteria developed in 1963. In rural areas of the country, the prevalence of „defined” RA was $0.12 \%$ and for both „defined” and „probable” RA types was estimated at $0,87 \%$. There were examined 801 subjects aged over 15 years, belonging to a rural community of (Phokeng village located $100 \mathrm{~km}$ northwest of Johannesburg with a population around 10000 inhabitants) (11). In urban areas of South Africa, among black population, a high prevalence of RA was recorded: $1.4 \%$ among female population and $0.9 \%$ among the general population, aged over 15 years. The prevalence of „defined” and „probable" RA forms was $2.6 \%$ for men, $3.7 \%$ for women and $3.3 \%$ for the general population aged $>15$. This epidemiological study was prospective and included 946 people belonging to a district of Soweto community in Johannesburg. No obvious cause was shown, but the intra-race differences, sociological and environmental factors have been invoked to justify the big differences between the prevalence of RA registered in rural and urban areas of South Africa (12).

In 1979, in Kenya, seropositivity and clinical features of a study group of 76 patients with RA (defined and classic) were estimated (13). Demographic characteristics (age, F/M ratio) and joint damage pattern were similar to the European population or to that of USA, but different from those of patients in Nigeria and South Africa. Most of the patients with defined AR (77\%) were seropositive, numbers in discordanance with those reported in Nigeria 10 years ago. The idea of a collaborative study between East and West Africa was actually suggested before, by a memorandum of World Health Organization in 1974, in order to elucidate the cause of the differences between Eastern and Western parts of Central Africa. However, similar to other studies conducted in Africa, here, it was also noted the absence of extraarticular systemic manifestations and the minor reduction of functional status.

\section{RA EPIDEMIOLOGICAL DATA IN ASIA (MONGOLOID RACE)}

First data on the incidence and prevalence of RA in Japan are published in 1965, RA diagnosis fullfilling 1958 American Rheumatology Association (ARA) criteria. Between 1958-1964, the prevalence and incidence of RA was assessed in two cities victims of the atomic bomb: Hiroshima and Nagasaki. There were investigated, at least once, around 16,000 subjects, aged $>15$ years, and 14,000 of them were reviewed two years later. During the first examination in Hiroshima, 79 cases of RA (of the 11,306 screened subjects) were identified, estimating a prevalence of the disease of $0.39 \%$, while in Nagasaki there were 23 cases of the 4,963 examined, which corresponded to a prevalence of $0.26 \%$. After two years, during the second examination, 10 subjects from Hiroshima and 4 from Nagasaki developed symptoms of RA, revealing a cumulative incidence of $0.09 \%$ for the two cities, similar to the incidence of Tecumseh, Michigan (14).

In 1966, the prevalence of rheumatic diseases, including RA was assessed in urban and rural populations of Japan, located in two suburbs of Osaka. It was established, according to 1958 ARA criteria, a cumulative prevalence of $0.5 \%$ for „defined” rheumatoid arthritis (10 cases) and ,probable” (5 cases) in the population aged over 20 years, with no differences between urban and rural areas (15).

For 30 years, between 1965-1996, in Okka and Iwata areas of Kamitonda Province in Japan, 16 new cases of RA according to 1958 ARA criteria (8 women and 8 men) were identified. The study population in this area was about 3,000 inhabitants, Kamitonda Province having a population of 22,591 (in 1965 ) to 32,268 (in 1996) inhabitants. Statistical analysis of RA incidence divided over 3 decades (1965-1975, 1975-1985, 1985-1996) showed a decreasing current: 0.35 cases/1000 $(35 / 100,000)$ persons per year (1965-1975) to $0.09 / 1000(9 / 100,000)$ people per year (1985-1996). Four of the 16 cases were in complete remission at the end of follow-up; these 4 cases were characterized by the absence of RF or its intermittent presence (in two cases) or late appearance (after 17, respectively 21 years in the other 2 cases) of osteoerosive lesions. The prevalence of the disease during this period ranged from 0.2 to $0.47 \%$. These values had a decreasing trend especially for female gender (6). 
RA epidemiology data are published in 1993 in Indonesia, representing the results of a population study conducted in rural and urban areas of this country. They showed a low prevalence of RA: $0.2 \%$ and $0.3 \%$ in both rural and urban population areas. The study included more than 5,000 subjects aged over 15 year (4,683 from rural areas and 1071 from urban areas): patients with persistent peripheral arthritis ( $>6$ weeks) were examined by a rheumatologist and underwent serological tests and radiological examinations. Low prevalence of the disease compared to developed countries was also connected with different age structure, resulting from reduced life expectancy of the population of Indonesian archipelago (16).

In China, Rheumatology is a relatively new medical specialty and the first Rheumatology department was established in 1980 in Peking Union Medical College Hospital; most data on the epidemiology of the rheumatic diseases in China occur after this date, a great number of them being results of population studies carried out under COPCORD (Community Oriented Program for Control of Rheumatic Diseases) initiative.

COPCORD is a program initiated by the World Health Organization (World Health Organization WHO) and the International League Against Rheumatism (ILAR) more than 30 years ago (Geneva, 1981). This program includes population studies that assessed the prevalence of rheumatic diseases in developing countries located in Asia Pacific area (India, Indonesia, China, Thailand, Bangladesh, Malaysia, etc.), in the Middle East, South America (Brazil, Argentina), Cuba, Mexico. COPCORD methodology of population studies include: (1) identification of cases, (2) registration of symptoms, (3) evaluation by a rheumatologist (17).

The first population-based study of the epidemiology of rheumatic diseases in China, including RA, compares the prevalence of the disease in rural areas of the North (the study sample had 4,192 inhabitants) with rural areas in the South (the study sample had 5,057 inhabitants) and the results showed a similar prevalence of RA: $0.34 \%$ in the North and $0.32 \%$ in the South, both numbers parallel to the rural areas of Japan (18). In Taiwan Island, RA recorded an increased prevalence of $0.93 \%$ in urban areas and a prevalence of $0.26 \%$ in rural area, similar to that recorded in mainland China (19). The urban and suburban areas of Taiwan have the highest prevalence of the disease $(0.93 \%)$ possibly in connection with the superior development of this zone compared to mainland China, socioeconomic status being known as a possible risk factor for the disease. The COPCORD population stud on the prevalence of RA and other rheumatic diseases (gout, ankylosing spondylitis, osteoarthritis, articular rheumatism) in Shanghai's urban population took place between September 1997 and March 1998 and included 4 communities (of the 13 communities of the city) with 7,603 people aged over 15 years. 6,584 adults (3,394 women and $3,190 \mathrm{men}$ ) were interviewed with a response rate of $86.6 \%$ which led to a prevalence of $0.28 \%$ for RA (RA diagnosis according to 1958 ARA criteria), lower when compared to RA prevalence in Europe and especially in Western Europe countries. (20)

In 2008, results of a meta-analysis that included 15 population studies were published. The studies included were conducted between 1987 and 1990 in 10 provinces/cities of mainland China and islands and summed a total of 94,297 adults. For rheumatoid arthritis, defined by ACR criteria, it was reported a prevalence of 0.2 to $0.37 \%$ in mainland China with no significant differences between North and South, between urban and rural areas or between different ethnic groups (21). The prevalence of RA in mainland China is similar to other Asian countries (Philippines, Thailand, India, Indonesia), to the countries of South America (Brazil, Mexico), but lower than the one in Caucasian population (21). The latest data on the epidemiology of RA in China were published in 2012: they represent the results of a population-based study that included a large number of participants $(10,556$ subjects aged $\geq 16$ years, 5,223 $49.48 \%$ men and $5,333-50.52 \%$ women) living in Beijing district. The prevalence of rheumatoid arthritis calculated in the total population is $0.28 \%$ with a significantly higher prevalence for women ( $0.46 \%$ vs. $0.08 \%$ for men) and a female-male ratio of $6: 1(22)$.

Two of the first Asian countries that had a benefit from COPCORD initiative are Philippines and Thailand. In Philippines, the prevalence of RA was assessed among urban population, while in Thailand they determined the prevalence of rheumatic diseases, including RA in rural areas. RA prevalence in urban areas of Philippines is $0.17 \%$, a lower one compared to other Asian developing countries. These numbers represent the results of a COPCORD population-based study that included a sample of 3,065 adult residents in the metropolitan area of Manila (4). For the rural population of Thailand it has been estimated an 
RA prevalence of $0.12 \%$. The study included 2,463 subjects aged $\geq 15$ years from rural areas, who were assessed according to the same COPCORD questionnaire used in other Asian countries (Vietnam, Philippines, Indonesia) (23).

A prevalence of $0.28 \%$ for RA is estimated in Vietnam, in the urban adult population of the country. Data are provided by a COPCORD study which included 2,119 subjects aged $\geq 16$ years from urban areas of Vietnam (24). For Malaysia, a population-based study, initiated again by COPCORD, reveals the unusual presence of inflammatory rheumatism in a semirural community of this country with multiracial population (Malaysian, Chinese, Indian) (25).

The first report on the prevalence and incidence of RA among the entire population of South Korea was published in 2013: using data from the National Health Insurance System of South Korea, the prevalence of RA among the general population was $0.26 \%$ (95\%
CI $0.25-0.27)$ in $2006,0.27 \%(95 \%$ CI $0.26-0.28)$ in 2007 , and $0.27 \%$ (95\% CI $0.26-0.28)$ in 2008 . The incidence of RA in the general population was estimated at $42 / 100,000(95 \%$ CI 29.3-54.7) in 2008. Epidemiological data on the incidence and prevalence of RA in the general population in Korea are comparable to those of other Asian countries (26).

From the existing data, some general conclusions may be drawn regarding the epidemiology of RA in non-Caucasian populations: highest prevalence registers in Native Americans population- Pima Indian tribes, Chippewa and Yakima $(\sim 5.3 \%)$ and lowest in people from China and Japan $(0.2 \%-0.3 \%)$. Yet, comparisons of RA prevalence in different populations are difficult to interpret unless standardized methods are used. Real reasons for ethnic differences in risk of RA are still unknown and they deserve further investigations.

\section{REFERENCES}

1. Silman A.J. In: Silman A.J., Hochberg M.C., Eds. Epidemiology of the rheumatic diseases. 2nd ed. Oxford, Oxford University Press 2001; pp. 31-71

2. del Puente A., Knowler W.C., Pettit D.J., Bennett P.H. High incidence and prevalence of rheumatoid arthritis in Pima Indians. Am J Epidemiol 1989, 129:1170-1178.

3. Harvey J., Lotze M., Stevens M.B. et al. Rheumatoid arthritis in a Chippewa band. I. Pilot screening study of disease prevalence. Arthritis Rheum 1981, 24:717- 721.

4. Dans L.F., TankehTorres S., Amante C.M., Penserga E.G. The prevalence of rheumatic diseases in a Filipino urban population: a WHO-ILAR COPCORD study. J Rheumatol 1997, 24:1814-1819;

5. Zeng Q., Huang S., Chen R. 10-year epidemiological study on rheumatic diseases in Shantou area. Zhonghua Nei Ke Za Zhi 1997, 36:193-197;

6. Shichikawa K., Inoue K., Hirota S. et al. Changes in the incidence and prevalence of rheumatoid arthritis in Kamitonda, Wakayama, Japan, 1965-1996. Ann Rheum Dis 1999, 58:751-756).

7. Molokhia M., McKeigue P. Risk for rheumatic disease in relation to ethnicity and admixture. Arthritis Res 2000; 2:115-25

8. Pelaez-Ballestas I., Sanin L.H., Moreno-Montoya J. et al. Epidemiology of the rheumatic diseases in Mexico. A study of 5 regions based on the COPCORD methodology. J Rheumatol 2011; 86(Suppl):3

9. Greenwood B.M. et al. Poliarthtis in Western Nigeria. Rheumatoid Arthris. Ann. rheum. Dis. (1969), 28, 488.

10. Muller A.S. Population Studies on the Prevalence of Rheumatic Diseases in Liberia and Nigeria. MD Thesis, 1970, University of Leiden

11. Beighton P., Solomon L., Valkenburg H.A. Rheumatoid arthritis in a rural South African Negro population. Annals ofthe Rheumatic Diseases, 1975,34, 136.

12. Solomon L., Robin G., Valkenburg, H.A. Rheumatoid arthritis in an urban South African Negro population. Annals ofthe Rheumatic Diseases, 1975, 34, 128

13. Bagg L.R. et al. Rheumatoid arthritis in Kenya. I. Clinical observations. Annals of the Rheumatic Diseases, 1979, 38, 23-25;
14. Wood J.W., Kato H., Johnson K.G. et al. Rheumatoid arthritis in Hiroshima and Nagasaki, Japan. Prevalence, incidence, and clinical characteristics. Arthritis Rheum. 1967 Feb;10(1):21-31).

15. Kanji Shichikawa et al. Rheumatic Complaints in Urban and Rural Populations in Osaka, Ann. rheum. Dis. (1966), 25

16. Darmawan J, Muirden KD, Valkenburg HA et al. The epidemiology of rheumatoid arthritis in Indonesia. Br J Rheumatol 1993; 32:537_40

17. Arvind Chopra, COPCORD, ACR 2007

18. Wigley R.D. et al. Rheumatic diseases in China: ILAR-China study comparing the prevalence of rheumatic symptoms in northern and southern rural populations. J Rheumatol. 1994 Aug; 21(8): 1484-90

19. Chou C.T., Pei L., Chang D.M. et al. Prevalence of rheumatic diseases in Taiwan: a population study of urban, suburban, rural differences. J Rheumatol 1994, 21:302-306).

20. Dai S.M., Han X.H., Zhao D.B. et al. Prevalence of rheumatic symptoms, rheumatoid arthritis, ankylosing spondylitis, and gout in Shanghai, China: a COPCORD study. J Rheumatol. 2003 Oct; 30(10):2245-51

21. Qing Yu Zeng, Ren Chen, John Darmawan et al. Rheumatic Diseases in China. Arthritis Research \& Therapy 2008

22. Ru Li, Jian Sun, Li-Min Ren, Hong-Yu Wang et al. Epidemiology of eight common rheumatic diseases in China: a large-scale crosssectional survey in Beijing. Rheumatology 2012; 51:721-729)

23. Chaiamnuay P., Darmawan J., Muirden K.D., Assawatanabodee P. Epidemiology of Rheumatic disease in rural Thailand: a WHOILAR COPCORD study. J Rheumatol 1998, 25:1382-1387).

24. Minh H.T.T., Darmawan J., Chen S.L. et al. Prevalence of the rheumatic diseases in urban Vietnam: a WHO-ILAR COPCORD study. J Rheumatol 2003;30:2252

25. Veerapen K., Wigley R.D., Valkenburg H. Musculoskeletal pain in Malaysia : a COPCORD survey. J Rheumatol. 2007 Jan; 34(1):20713).

26. Sung Y.K., Cho S.K., Choi C.B., Bae S.C. Prevalence and incidence of rheumatoid arthritis in South Korea. Rheumatol Int. 2013 Jun; 33(6):1525-32 